\title{
Effects of rilpivirine, $17 \beta$-estradiol and $\beta$-naphthoflavone on the inflammatory status of release of adipocytokines in 3T3-L1 adipocytes in vitro
}

\author{
Shalini Behl ${ }^{1} \cdot$ Abdu Adem $^{2} \cdot$ Arif Hussain $^{3} \cdot$ Jaipaul Singh ${ }^{1}$ \\ Received: 27 August 2018 / Accepted: 5 February 2019 / Published online: 29 March 2019 \\ (c) The Author(s) 2019
}

\begin{abstract}
Rilpivirine is a non-nucleoside reverse transcriptase inhibitor, recently developed as a drug of choice for initial anti-retroviral (ARV) treatment of HIV-1 infection, whereas estradiol is a major component of hormonal contraceptives. Both drugs have effects on lipid metabolism, impairment of adipocyte differentiation and alteration of adipose tissue distribution and function. This study investigated the effects of different concentrations of either rilpivirine or estradiol either alone or in combination on adipocyte differentiation and adipocytokines status in vitro in the absence and presence of $\beta$-naphthoflavone, (BNF),a potent agonist of the aryl hydrocarbon receptor. 3T3-L1 human pre-adipocytes were cultured and differentiated with different concentrations of treatment drugs. After 10 days of differentiation procedure, cells were examined for their morphology and viability. Glycerol,adiponectin, leptin, resistin and interleukin-8 (IL-8) were quantified using commercially available kits. The results show that either rilpivirine or estradiol individually or during their combination can evoke significant increases in glycerol release and a concomitant significant decrease of adiponectin from adipocytes. These effects were dose-dependent. The effects of combined treatments were much larger than individual concentration for each drug. Both drugs had little of no effect on leptin levels, except for a small decrease with $10 \mu \mathrm{M}$ rilpivirine alone or when combined with estradiol. In addition, both drugs evoked small increases in the release of resistin and interleukin- 8 with significant values at higher doses compared to untreated adipocytes. When adipocytes were pretreated with BNF, either rilpivirine or, estradiol or when combined evoked a much larger release in glycerol and a much larger decrease in adiponectin compared to the absence of BNF. In contrast, BNF pretreatment had little of no effect on either leptin, resistin or IL-8 metabolism compared to the results obtained in the presence of either rilpivirine or estradiol alone or in combination. These results show that rilpivirine and estradiol either alone or when combined or pretreated with BNF can evoke marked effects on glycerol and cytokines levels from adipocytes. However, their mechanism (s) in inducing adipogenesis warrants further investigation of different transcription factors at gene expression levels.
\end{abstract}

Keywords Adipocytes $\cdot$ Rilpivirine $\cdot$ Estradiol $\cdot \beta$-Naphthoflavone $\cdot$ Adiponectin $\cdot$ Leptin $\cdot$ Resistin and IL-8

Shalini Behl

SBehl@uclan.ac.uk; behl.shalini@gmail.com

Abdu Adem

abdu.adem@uaeu.ac.ae

Arif Hussain

arifhussain@manipaldubai.com

Jaipaul Singh

jsingh3@uclan.ac.uk
1 School of Forensic and Applied Sciences, University of Central Lancashire, Preston, Lancashire PR1 2HE, England, UK

2 Department of Pharmacology, United Arab Emirates University, Al Ain, United Arab Emirates

3 School of Life Sciences, Manipal University, Academic City, Dubai, United Arab Emirates 


\section{Introduction}

Obesity is a major global health problem and if left untreated, it may lead to major complications [1]. It is attributed to a number of factors including over-eating, sedentary lifestyle, lack of physical activity, genetics, diets rich in carbohydrate, frequency of eating, hormonal and various psychological factors as well as others. Some medications are also associated with weight gain. These include certain anti-depressants, anti-convulsants, some diabetes medication and certain hormones including leptin, insulin, estrogens, androgens and growth hormones $[2,3]$.

Rilpivirine is a prescription medicine for the treatment of HIV infection in adults and children. Although the approval document of rilpivirine issued in 2011 by the U.S. Food and Drug Administration (FDA) included fat re-distribution among its warnings and precautions, contradictory results showing its effect on the adipose tissue distribution and function have been presented by previously conducted clinical trials [4-7]. On the other hand, $17 \beta$-estradiol is a major component of hormonal contraceptives and it acts primarily as an agonist of the estrogen receptor (ER). Several studies have provided evidence of a hormonal regulation of pre-adipocyte proliferation $[8,9]$. Estrogen promotes subcutaneous fat and regulate adipose tissue distribution through its receptors, ER $\alpha$ and ER $\beta$ $[10,11]$. 17 $\beta$-estradiol has been shown to have stimulatory effects on proliferation of female rat pre-adipocytes [12] and in human pre-adipocytes [13].

The British HIV guideline for the management of HIV infection indicated that rilpivirine is an appealing option to consider in women of childbearing potential. At the same time, it also warns of the significant pharmacokinetic and pharmaco-dynamic interactions that have been reported between the anti-retroviral (ARV) drugs and hormonal agents. Inducers of hepatic enzymes by ARVs may result in increased breakdown of estrogen that can compromise contraceptive efficacy [14]. In addition, both of these drugs are known to alter lipid metabolism and fat distribution in the body $[15,16]$. Therefore, a mechanistic insight into the elucidative role of concomitant use of rilpivirine and estradiol would provide more robust and reliable prediction of their potential interactions on the adipogenesis pathway.

Organic pollutants such as $\beta$-naphthoflavone (BNF) tend to escape from the body metabolic system and accumulate in the white adipose tissue (WAT), thereby affecting its physiological role, leading to the development of obesity-related disorders [17]. The mechanisms through which such chemicals modulate the differentiation, metabolism, and secretory function of adipocytes are numerous
[18-21]. Aryl hydrocarbon receptor (AhR), a cytosolic ligand-activated transcription factor that participates in a variety of metabolic processes, including detoxification and adipogenesis, has been reported to be functionally present in rodent adipose tissue [17, 22]. Activated AhR modulates expressions of various genes involved in xenobiotic-metabolizing pathways, such as cytochrome P4501A1 (CYP1A1) [23-25]. CYP1A induction may be used as a biomarker of exposure to toxic substances in order to ascertain whether in vitro models could be useful in investigating the bio activation potential of environmental contaminants. Therefore, this study investigated the effect of rilpivirine and estradiol either alone or in combination on the adipose cells measuring free glycerol and a number of inflammatory markers including leptin, and adiponectin, resistin and IL- 8 which are associated with adipocyte function. In another series of experiments, rilpivirine and estradiol were combined with an environmental pollutant, BNF to determine any inhibitory or stimulating effects.

\section{Materials and methods}

\section{Material}

Adipose derived mesenchymal stem cells were obtained from Himedia ${ }^{\mathrm{TM}}$ Cat.\# CCK011. Complete medium and adipogeneic differentiation medium were also purchased from Himedia Cat.\# AL521 and Cat.\# AL537 respectively. Cytotoxicity kit was purchased from Promega ${ }^{\mathrm{TM}}$ Cat.\# G1780 to check the cell viability. Free glycerol and Adiponectin were measured using Abcam's Lipolysis Assay kit (Cat. \#ab185433) and Human Adiponectin ELISA kit (Cat.\#ab99968). Other adipocytokines were quantified using the kits from Sigma Aldrich: Human Leptin Elisa kit (RAB0333), Human Interleukin-8(IL-8) kit (Cat. \# RAB0319) and Human resistin ELISA kit (Cat. \# RAb0419).

\section{Cell proliferation, seeding and differentiation}

3T3-L1 adipose cells were incubated for $3-4 \mathrm{~h}$ in a humidified $\mathrm{CO}_{2}$ incubator with $5 \% \mathrm{CO}_{2}$ at $37{ }^{\circ} \mathrm{C}$ temperature and then replenished with complete medium. Cells were subcultured after reaching $70-80 \%$ confluency by gently aspirating the spent medium and washing the cells with $2-3 \mathrm{ml}$ of Dulbecco's phosphate buffer saline (DPBS). Fresh flasks were seeded at a density of approx. $0.125 \times 106$ cells $/ \mathrm{cm}^{2}$ of the flask. This seeding density was recommended as per the manufacturer's instructions (Himedia Cat.\# CL007). Differentiation into adipose cells was done in the presence of the same culture medium as used before and supplemented with adipogenic differentiation medium. 
Addition of treatment drugs was initiated on day 0 and continued throughout the differentiation period of 10 days. Fresh drugs were added each time the medium was replaced. The medium was replaced every 2-3 days. Stock solutions of 17- $\beta$ estradiol and BNF were prepared in differentiation medium while DMSO was used for preparing rilpivirine. They were then aliquoted and stored at $-20{ }^{\circ} \mathrm{C}$ prior to use. Working solutions of the treatment drugs were prepared by diluting them further.

\section{Lactate dehydrogenase assay for the measurement of cell viability}

Potential cytotoxic effects of drugs were determined using a CytoTox 96 non-radioactive cytotoxicity kit following the manufacturer's protocol. Cell viability was assessed on day 0 , 5 and 10.CytoTox $96 \AA$ reagent was added to each well containing the sample and incubated for $30 \mathrm{~min}$. Stop Solution was added, and the absorbance signal was measured at $490 \mathrm{~nm}$.

\section{Quantification of free glycerol}

Commercially available Abcam's Lipolysis Assay kit was used to measure glycerol released from 3T3-L1 cells. A volume of $0,2,4,6,8$ and $10 \mu \mathrm{L}$ of $1 \mathrm{mM}$ glycerol standard was added into series of wells to generate $0,2,4,6,8$ and $10 \mathrm{nmol} /$ well of glycerol standards and the volume of each well was adjusted to $50 \mu \mathrm{L}$ with Glycerol assay buffer followed by $50 \mu \mathrm{L}$ of the reaction mixture. Incubation was done for $30 \mathrm{~min}$ and absorbance was read at $570 \mathrm{~nm}$. Sample readings were applied to the standard curve to get nmol of glycerol amount in the sample wells.

\section{Quantification of inflammatory adipocytokines}

The concentrations of adipokines and cytokines released by adipocytes following treatment with the drugs and accumulated in the cell culture medium were measured at the end of 10 days of differentiation process employing established specific assay kits.

Commercially available Human Leptin Elisa kit was used for the quantitative measurement of leptin in cell culture supernatant. Standards were prepared by subsequent serial dilution of leptin standard using $1 \mathrm{X}$ Assay diluent B. A volume of $100 \mu \mathrm{L}$ of each standard and sample was added into appropriate wells and incubated overnight at $4{ }^{\circ} \mathrm{C}$. The plate was washed four times with $300 \mu \mathrm{L}$ of Wash Buffer. After this, $100 \mu \mathrm{L}$ of $1 \mathrm{X}$ Detection Antibody was added and incubated for $1 \mathrm{~h}$ followed by washing step. A volume of $100 \mu \mathrm{L}$ of HRP-Streptavidin was added to each well and incubated for $45 \mathrm{~min}$. The plate was washed again and $100 \mu \mathrm{L}$ of TMB reagent was added to each well. It was then incubated for $30 \mathrm{~min}$. Reaction was stopped by adding $50 \mu \mathrm{L}$ of Stop solution and absorbance was taken at $450 \mathrm{~nm}$. Sample concentrations were calculated using the equation of the standard curve.

Abcam's Human Adiponectin ELISA kit was used for the quantitative measurement of human adiponectin in cell culture supernatant following the manufacturer's instructions. Serially diluted standards were prepared using adiponectin stock standard. A volume of $100 \mu \mathrm{L}$ of each standard and sample was added into appropriate wells and incubated overnight at $4{ }^{\circ} \mathrm{C}$. Wells were washed four times with $300 \mu \mathrm{L}$ of $1 \mathrm{X}$ wash solution. After this, a volume of $100 \mu \mathrm{L}$ of $1 \mathrm{X}$ biotinylated detection antibody was added to each well and incubated for $1 \mathrm{~h}$. Wells were washed as before and $100 \mu \mathrm{L}$ of $1 \mathrm{X}$ HRP-streptavidin solution was added to each well and incubated for $45 \mathrm{~min}$. A volume of $100 \mu \mathrm{L}$ TMB substrate reagent was added followed by 30 min of incubation. Reaction was stopped by $50 \mu \mathrm{L}$ of stop solution and absorbance was read at $450 \mathrm{~nm}$.

Human interleukin-8 (IL-8) kit was used for the quantitative measurement of IL- 8 from cell culture supernatant following the manufacturer's protocol. Serial dilution was performed to prepare standards. Assay Diluent B served as the zero standard $(0 \mathrm{pg} / \mathrm{mL})$. A volume of $100 \mu \mathrm{L}$ of either standard or sample was added into appropriate wells and incubated for $2.5 \mathrm{~h}$. The wells were washed four times with $300 \mu \mathrm{L}$ of $1 \mathrm{X}$ wash solution. After this, $100 \mu \mathrm{L}$ of $1 \mathrm{X}$ prepared biotinylated detection antibody and incubated for $1 \mathrm{~h}$. A volume of $100 \mu \mathrm{L}$ of prepared HRP-streptavidin solution was then added and incubated for $45 \mathrm{~min}$ followed by $100 \mu \mathrm{L}$ of TMB reagent and $30 \mathrm{~min}$ incubation. Finally, a volume of $50 \mu \mathrm{L}$ of stop solution was added and absorbance was read at $450 \mathrm{~nm}$. Sample concentrations were calculated using the equation from the standard curve.

Resistin was quantified from the cell culture supernatant using the human resistin ELISA kit following the protocol from the manufacturer. Serially diluted standards were prepared using resistin stock standard. A volume of $100 \mu \mathrm{L}$ of standard or sample was added into appropriate wells and incubated for $2.5 \mathrm{~h}$. Wells were washed four times with $300 \mu \mathrm{L}$ of $1 \mathrm{X}$ wash solution followed by $100 \mu \mathrm{L}$ of $1 \mathrm{X}$ prepared biotinylated detection Antibody and 1-h incubation. After this, a volume of $100 \mu \mathrm{L}$ of HRP-streptavidin was added to each well and incubated for $45 \mathrm{~min}$. After washing, a volume of $100 \mu \mathrm{L}$ of TMB Reagent was added and incubated for $30 \mathrm{~min}$. Finally, a volume of $50 \mu \mathrm{L}$ of stop solution was added and absorbance was read at $450 \mathrm{~nm}$.Sample concentrations were calculated using the equation from the standard curve. 


\section{Statistical analysis}

All control and test data were analyzed using the Mega Stat software from Microsoft Excel. Chi Square goodness of fit test was applied and the $p$ value was obtained. All data obtained were expressed as mean \pm standard deviation (S.D). Each experiment was repeated three times but performed in duplicate $(n=6)$ to ensure the accuracy of results. A value of $p<0.05$ was taken as significant.

\section{Results}

\section{Morphological examination}

Figure 1 shows human pre-adipocytes that were differentiated in culture in the presence of different concentrations of either rilpivirine or estradiol either alone or combined for a period of 10 days. The results show that untreated cells on day 0 display spindle shaped, fibroblast-like appearance with undetectable lipids. However, with the progression of adipogenesis, mature adipocytes attain a round shape and become laden with lipids.
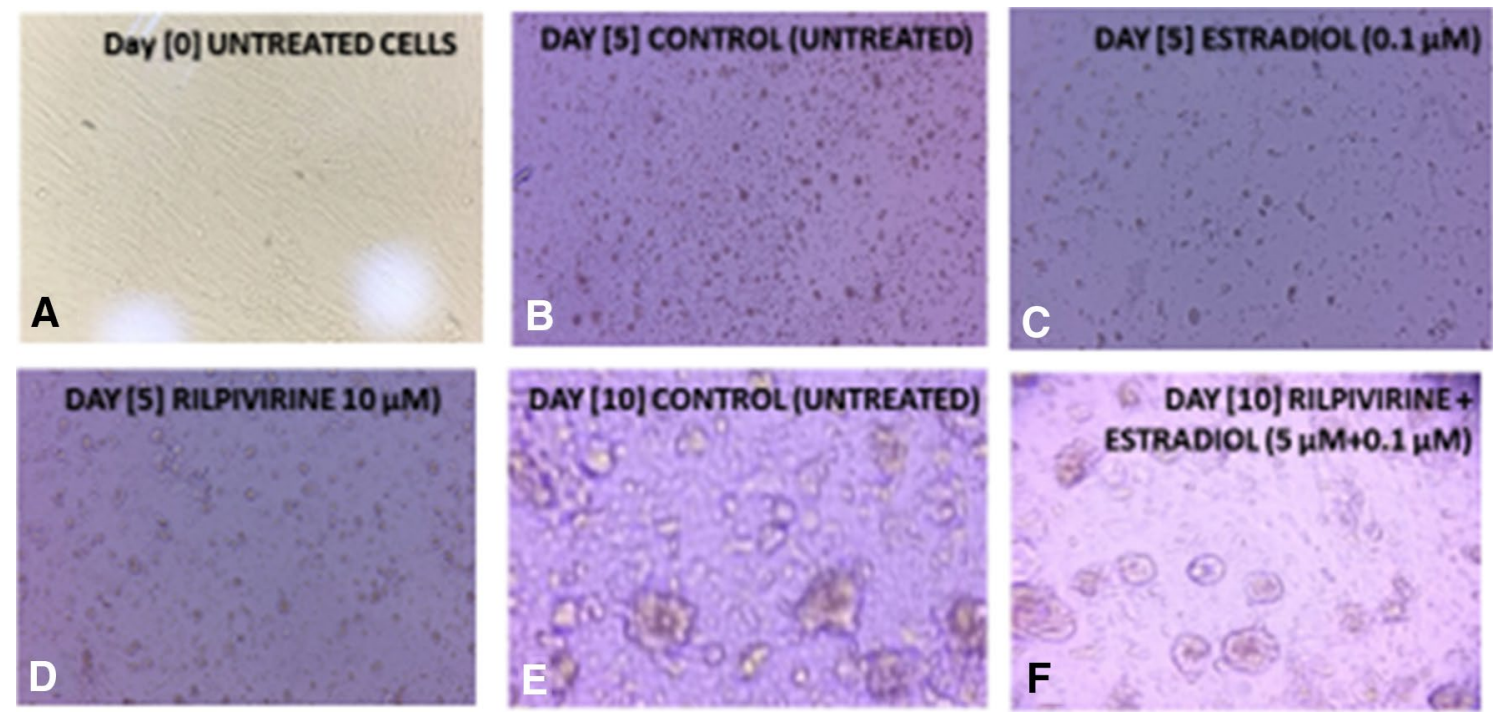

Fig. 1 Confocal image photographs $(\mathbf{a}-\mathbf{f})$ taken at $\times 10$ magnification of human adipocytes showing the effects of rilpivirine, estradiol and their combination on the morphology of the cells. Each image is typical of six such different experiments

Table 1 Cell viability measurement of human pre-adipocytes treated with rilpivirine and estradiol either alone or during combination

\begin{tabular}{|c|c|c|c|c|}
\hline \multirow[t]{2}{*}{ Drugs } & \multirow[t]{2}{*}{ Dosage $(\mu \mathrm{M})$} & \multicolumn{3}{|c|}{$\%$ Viability \pm SD } \\
\hline & & Day 0 & Day 5 & Day 10 \\
\hline Control & 0 & $97.23 \pm 0.003$ & $97.14 \pm 0.002$ & $96.47 \pm 0.006$ \\
\hline Rilpivirine & 1 & $97.27 \pm 0.006$ & $96.92 \pm 0.003$ & $96.71 \pm 0.006$ \\
\hline Rilpivirine & 5 & $96.89 \pm 0.013$ & $95.65 \pm 0.05$ & $95.17 \pm 0.01$ \\
\hline Rilpivirine & 10 & $97.23 \pm 0.006$ & $96.25 \pm 0.01$ & $95.82 \pm 0.01$ \\
\hline Estradiol & 0.01 & $97.27 \pm 0.006$ & $96.05 \pm 0.02$ & $95.68 \pm 0.01$ \\
\hline Estradiol & 0.05 & $97.13 \pm 0.002$ & $96.56 \pm 0.03$ & $95.86 \pm 0.01$ \\
\hline Estradiol & 0.1 & $97.23 \pm 0.003$ & $95.04 \pm 0.003$ & $95.68 \pm 0.008$ \\
\hline Rilpivirine + Estradiol & $1+0.01$ & $97.23 \pm 0.005$ & $95.69 \pm 0.04$ & $95.47 \pm 0.001$ \\
\hline Rilpivirine + Estradiol & $5+0.05$ & $97.58 \pm 0.013$ & $96.84 \pm 0.004$ & $94.71 \pm 0.01$ \\
\hline Rilpivirine + Estradiol & $10+0.1$ & $97.23 \pm 0.003$ & $95.89 \pm 0.04$ & $94.75 \pm 0.01$ \\
\hline
\end{tabular}

Pre-adipocytes were treated with the different concentrations of drugs for 10 days. Data are expressed as \% viability \pm SD relative to the control, $>0.05$ for treatment compared to control; $n=6$ 
Table 2 Cell viability of human pre-adipocytes treated with rilpivirine and estradiol either alone or in combination but in the continuous presence of $200 \mu$ M BNF: Pre-adipocytes were treated with the different concentrations of drugs for 10 days

\begin{tabular}{lllll}
\hline Drugs & Dosage $(\mu \mathrm{M})$ & \multicolumn{2}{l}{$\%$ Viability \pm SD } & \\
\cline { 3 - 5 } & & Day 0 & Day 5 & Day 10 \\
\hline Control & 0 & $97.23 \pm 0.004$ & $96.61 \pm 0.075$ & $96.64 \pm 0.03$ \\
Rilpivirine + BNF & $1+200$ & $97.06 \pm 0.005$ & $96.86 \pm 0.04$ & $96.22 \pm 0.004$ \\
Rilpivirine+BNF & $5+200$ & $97.23 \pm 0.003$ & $96.84 \pm 0.01$ & $96.82 \pm 0.01$ \\
Rilpivirine+BNF & $10+200$ & $97.23 \pm 0.003$ & $96.72 \pm 0.007$ & $96.22 \pm 0.001$ \\
Estradiol+BNF & $0.01+200$ & $97.16 \pm 0.009$ & $96.74 \pm 0.01$ & $96.47 \pm 0.004$ \\
Estradiol+BNF & $0.05+200$ & $97.09 \pm 0.004$ & $95.26 \pm 0.04$ & $96.54 \pm 0.01$ \\
Estradiol+BNF & $0.1+200$ & $97.23 \pm 0.006$ & $95.26 \pm 0.05$ & $96.82 \pm 0.01$ \\
Rilpivirine+Estradiol + BNF & $1+0.01+200$ & $97.09 \pm 0.003$ & $94.66 \pm 0.01$ & $96.43 \pm 0.007$ \\
Rilpivirine + Estradiol + BNF & $5+0.05+200$ & $96.96 \pm 0.002$ & $94.78 \pm 0.05$ & $96.78 \pm 0.02$ \\
Rilpivirine + Estradiol + BNF & $10+0.1+200$ & $97.09 \pm 0.004$ & $96.44 \pm 0.01$ & $96.43 \pm 0.01$ \\
\hline
\end{tabular}

Data are expressed as $\%$ viability \pm SD relative to the control; $p>0.05$ for control compared to treatments; $\mathrm{n}=6$

\section{Cell viability assessment}

Cell viability was assessed for the two series of three different experiments measured in duplicates $(n=6)$ by employing lactate dehydrogenase assay. The results are shown in Tables 1 and 2. Values were expressed as the percentage test cells surviving compared to control cells. The results in these tables show no significant $(p>0.05)$ difference in cell viability with drug treatments compared untreated control.

\section{Measurements of levels of free glycerol and adipocytokines in untreated and treated adipocytes after 10 days}

In this and subsequent figures, values are presented as means \pm SD from duplicate set of experiments expressed relative to values from untreated control cells. $n=6$;* $\mathrm{p}<0.05$ for control compared to drug treatments.

The data presented in Fig. 2 show the effects of different concentrations of either rilpivirine or estradiol alone or in combination on the release of free glycerol from human adipocytes. The results show that all drug treatments can evoke significant $(\mathrm{p}<0.05)$ increases in free glycerol release from human adipocytes compared to untreated control, except for $0.01 \mu \mathrm{M}$ estradiol, which induces only a small increase in free glycerol.

Figure 3 shows the effect of rilpivirine and estradiol either alone or in combination on the release of leptin by human adipocytes in culture for 10 days. The results show the different types of drug treatments had little or no effect on leptin release, except for $10 \mu \mathrm{M}$ rilpivirine alone or when it was combined with $0.1 \mu \mathrm{M}$ estradiol
Fig. 2 Bar charts showing the effects of different concentrations of either rilpivirine or estradiol alone or in combination on the release of free glycerol from human adipocytes following 10 days in culture

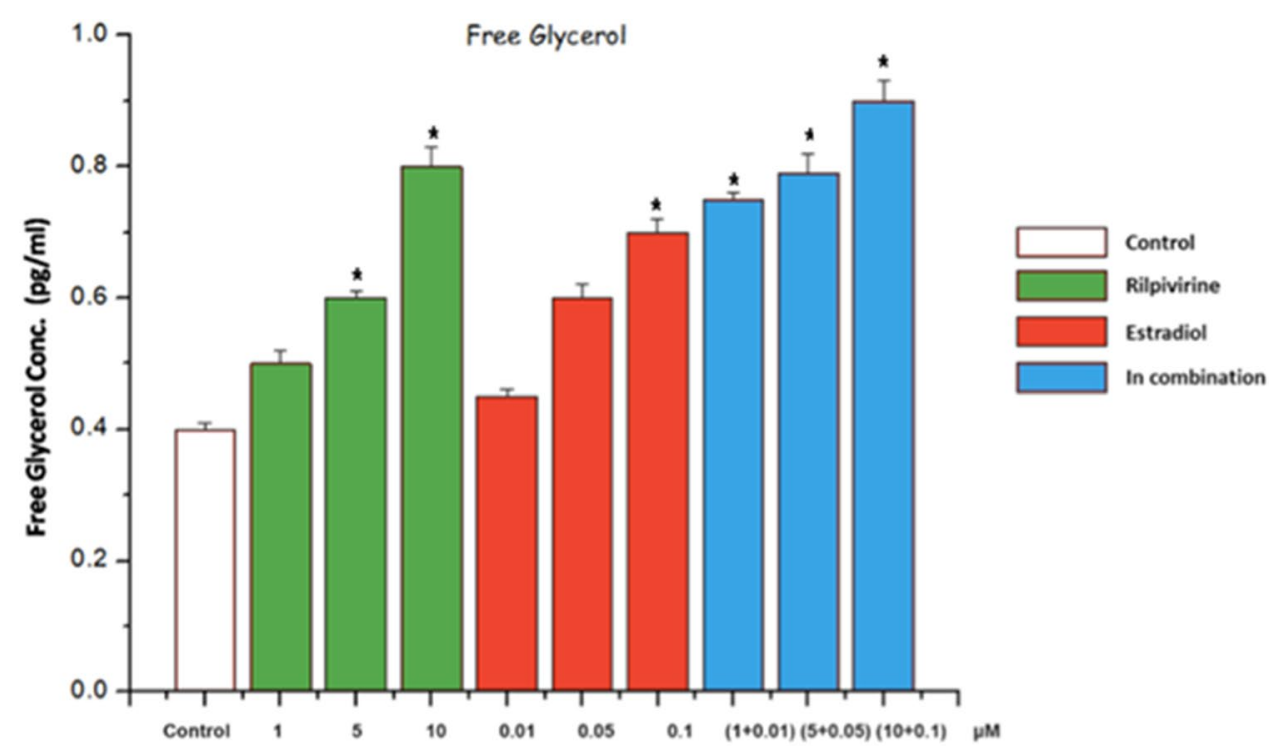


Fig. 3 Bar charts showing the effect of rilpivirine and estradiol either alone or in combination on the release of leptin by human adipocytes in culture for 10 days. Values are means $\pm \mathrm{SD}$; $* \mathrm{p}<0.05$ compared to untreated control cells; $\mathrm{n}=6$
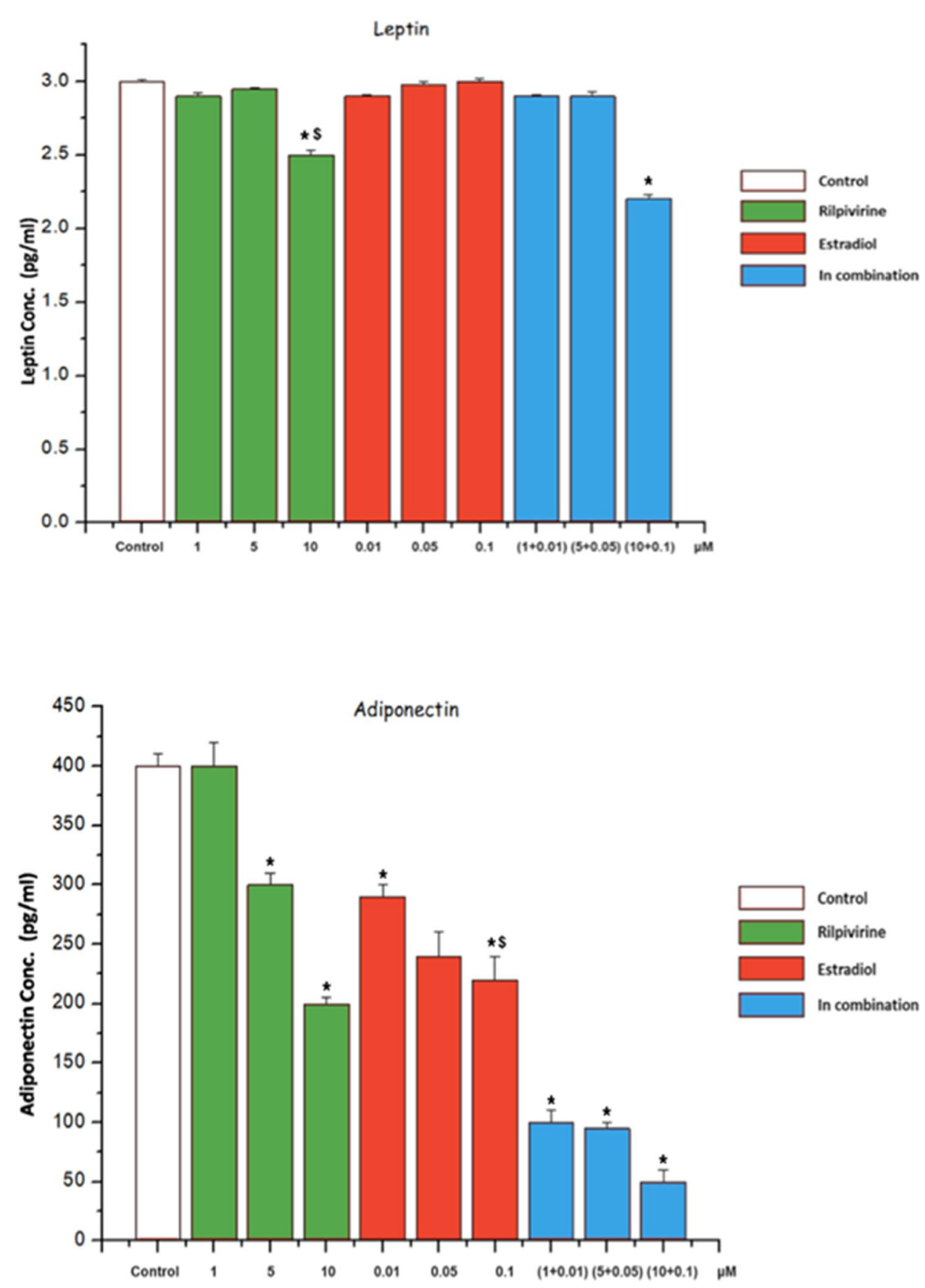

Fig. 4 Bar charts showing the effect of rilpivirine and estradiol either alone or in combination on the release of adiponectin from human adipocytes in culture for 10 days. Data are means $\pm \mathrm{SD}=6 ;{ }^{*} \mathrm{p}<0.05$ for all concentrations of the drugs compared to control, except for $1 \mu \mathrm{M}$ rilpivirine 
Fig. 5 Bar charts showing the effect of rilpivirine and estradiol either alone or in combination on the release of resistin from human adipocytes in culture for 10 days. Values are means $\pm \mathrm{SD} ; \mathrm{n}=6$; ${ }^{*} \mathrm{p}<0.05$ for all drug treatments compared to untreated control except for 1 and $5 \mu \mathrm{M}$ rilpivirine alone and when rilpivirine ( 1 and $5 \mu \mathrm{M})$ was combined with estradiol (0.1 and $0.5 \mu \mathrm{M})$
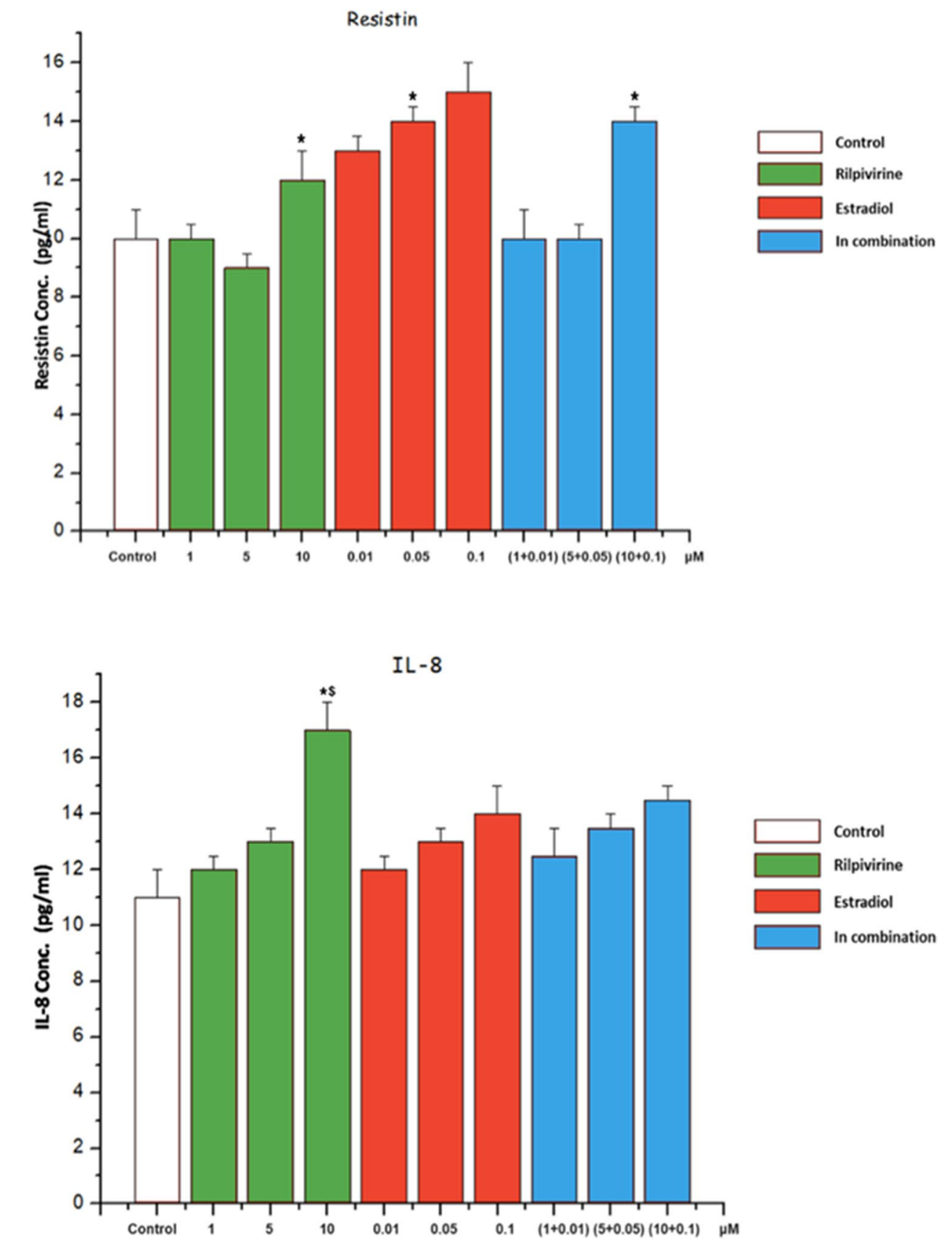

Fig. 6 Bar charts showing the effect of rilpivirine and estradiol either alone or in combination on the release of interleukin- 8 from human adipocytes in culture for 10 days. Data as means $\pm \mathrm{SD} ; \mathrm{n}=6 ;{ }^{*} \mathrm{p}<0.05$ for $10 \mu \mathrm{M}$ rilpivirine compared to untreated control
Figure 6 shows the effect of rilpivirine and estradiol either alone or in combination on the release of IL-8 from human adipocytes in culture for 10 days. The data reveal a significant $(\mathrm{p}<0.05)$ release in IL- 8 for only $10 \mu \mathrm{M}$ rilpivirine compared to untreated control. The other drug treatments only evoked small increases (but not significant, $\mathrm{p}>0.05$ ) in IL-8 compared to untreated control cells.

\section{Measurement of free glycerol and adipocytokines from human adipocytes treated with various concentrations of rilpivirine and estradiol either alone or in combination but in the continuous presence of $200 \mu \mathrm{M} \beta$-naphthoflavone (BNF)}

In this series of experiments the human adipocytes were pretreated with BNF followed by treatment with either rilpivirine or estradiol alone or during their combination employing different doses. The rationale was to ascertain whether 
BNF might exert an attenuating or potentiating effect on lipolysis and the release of adipocytokines from human adipocytes.

Figure 7 shows the effect of different doses of rilpivirine and estradiol either alone or following combination in the presence of $200 \mu \mathrm{M}$ of BNF on the release of free glycerol from human adipocytes in culture over 10 days with the drugs. The results show that all drug treatments can evoke significant $(\mathrm{p}<0.05)$ dose-dependent release in free glycerol compared to untreated control. These effects were much larger compared the results obtained in the absence of BNF (see Fig. 2 for comparison).

Figure 8 shows the effect of different concentrations of rilpivirine or estradiol either alone or in combination and in the presence of $200 \mu \mathrm{M}$ of BNF on the release of leptin by human adipocytes in culture for 10 days with the drugs. The results show that only $10 \mu \mathrm{M}$ rilpivirine alone and $10 \mu \mathrm{M}$ rilpivirine in combination with $0.1 \mu \mathrm{M}$ estradiol with $\mathrm{BNF}$
Fig. 7 Bar charts showing the effect of different concentrations of rilpivirine and estradiol either alone or following combination in the presence of $200 \mu \mathrm{M}$ of BNF on the release of free glycerol from human adipocytes in culture over 10 days with the drugs. In this and subsequent figures human pre-adipocytes were differentiated in culture in the presence of the indicated concentrations of drugs. Values are means $\pm \mathrm{SD} ; \mathrm{n}=6 ; * \mathrm{p}<0.05$ for all drug treatments compared to untreated control cells
Fig. 8 Bar charts showing the effect of different concentrations of rilpivirine or estradiol either alone or in combination and in the presence of $200 \mu \mathrm{M}$ of $\mathrm{BNF}$ on the release of leptin by human adipocytes in culture for 10 days with the drugs. Values are means $\pm \mathrm{SD} ; \mathrm{n}=6 ; * \mathrm{p}<0.05$
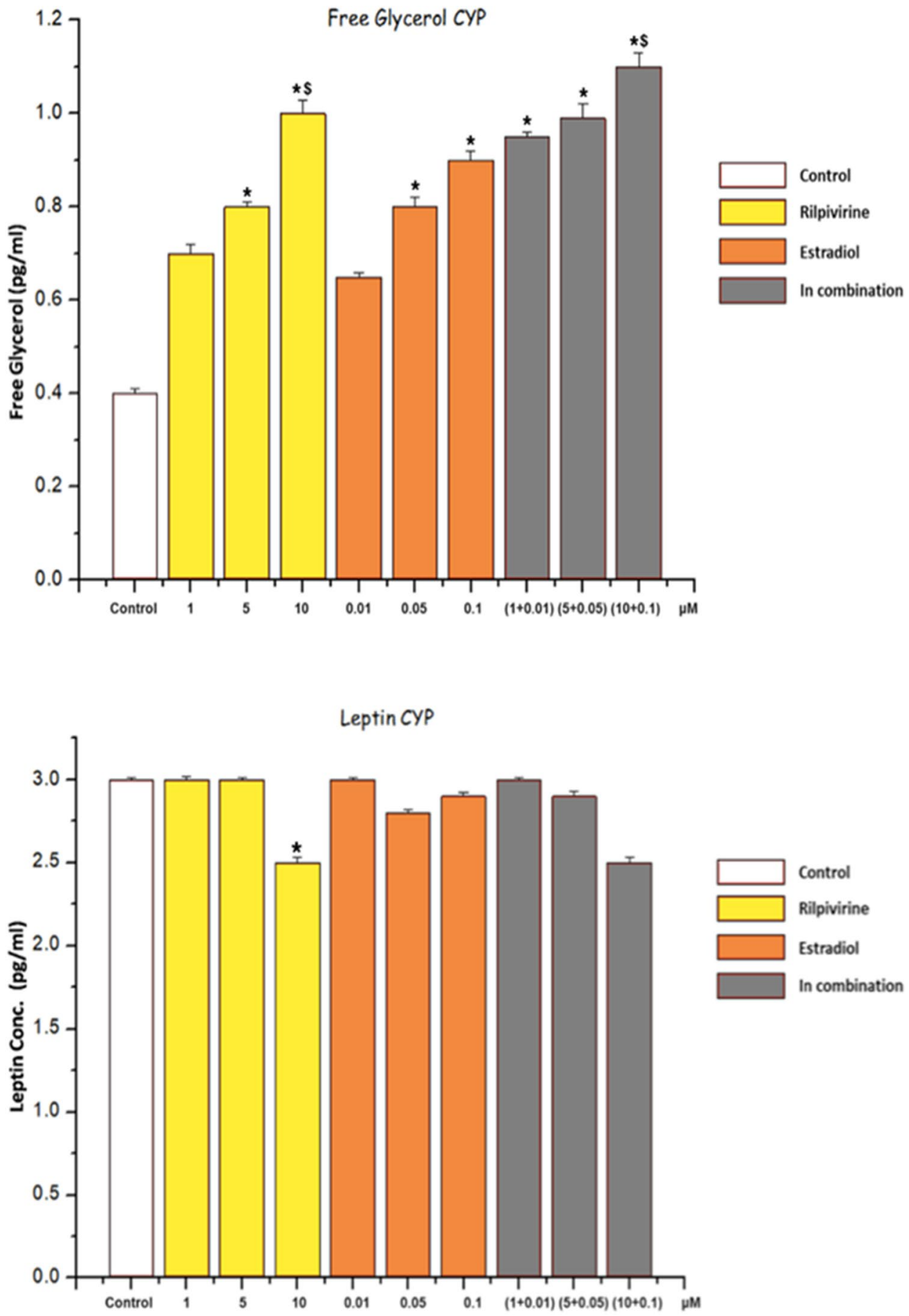
can evoke significant $(\mathrm{p}<0.05)$ decreases in leptin compared to untreated control.

Figure 9 shows the effect of different concentrations of rilpivirine and estradiol either alone or in combination and in the presence of $200 \mu \mathrm{M}$ of BNF on the release of adiponectin by human adipocytes in culture for 10 days with the drugs. The results show significant $(\mathrm{p}<0.05)$ decreases in adiponectin release for all drug treatments compared to untreated control. The decrease in adiponectin level was dose dependent, but much more marked in the presence of BNF.
Figure 10 shows the effect of rilpivirine and estradiol either alone or in combination and in the presence of $200 \mu \mathrm{M}$ of BNF on the release of resistin from human adipocytes in culture for all drugs. The results show a significant $(\mathrm{p}<0.05)$ release in resistin for $10 \mu \mathrm{M}$ rilpivirine, all concentrations of estradiol and rilpivirine $(10 \mu \mathrm{M})$ in combination with estradiol $(0.1 \mu \mathrm{M})$ and BNF compared to untreated control.

Figure 11 shows the effect rilpivirine and estradiol either alone or in combination and in the presence of $200 \mu \mathrm{M}$ of BNF on the release of IL-8 from human adipocytes in culture for 10 days with all the drugs. The results show a
Fig. 9 Bar graph showing the effect of different concentrations of rilpivirine and estradiol either alone or in combination and in the presence of $200 \mu \mathrm{M}$ of BNF on the release of adiponectin by human adipocytes in culture for 10 days with the drugs. Values are means $\pm \mathrm{SD} ; \mathrm{n}=6 ; * \mathrm{p}<0.05$ for all drug treatments compared to untreated control
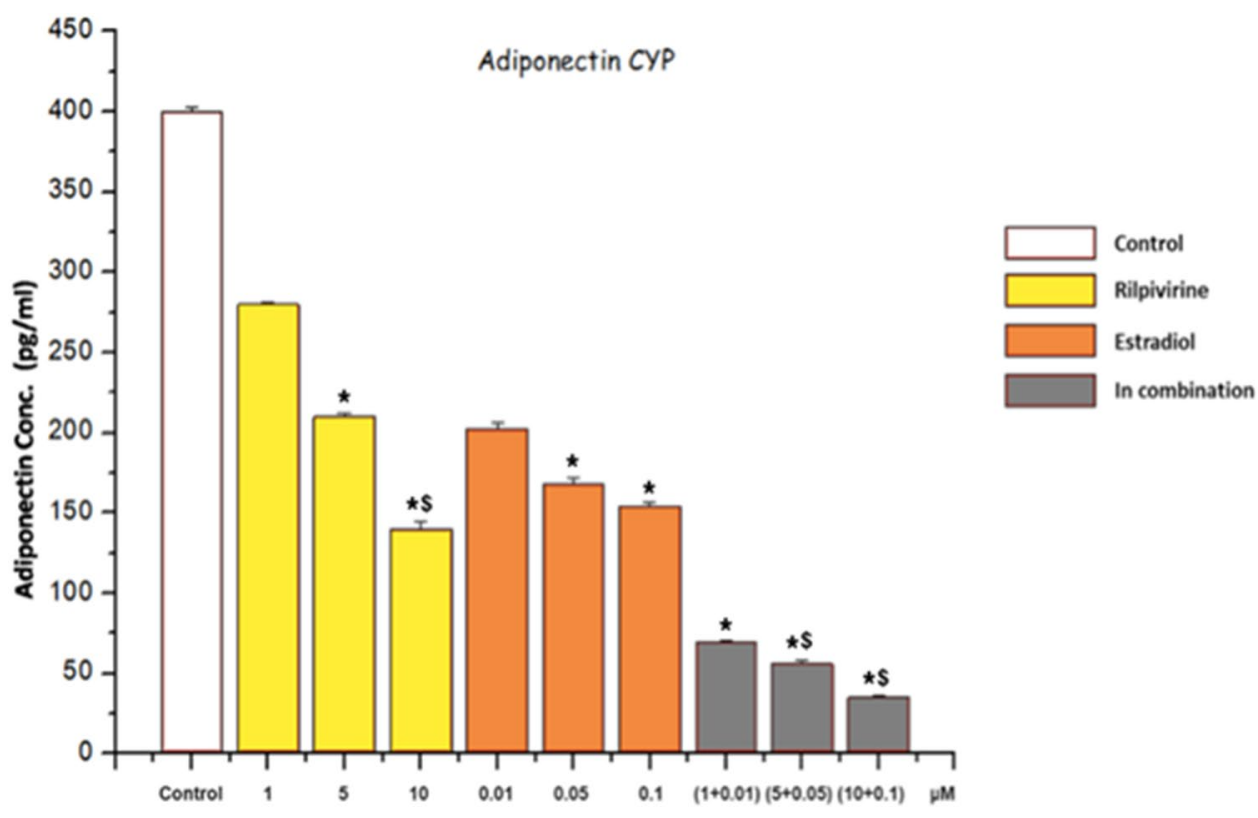

Fig. 10 Bar graph showing the effect of rilpivirine and estradiol either alone or in combination and in the presence of $200 \mu \mathrm{M}$ of BNF on the release of resistin from human adipocytes in culture for all the drugs. Values are means $\pm \mathrm{SD} ; \mathrm{n}=6 ; * \mathrm{p}<0.05$ for drug treated cells untreated control cells

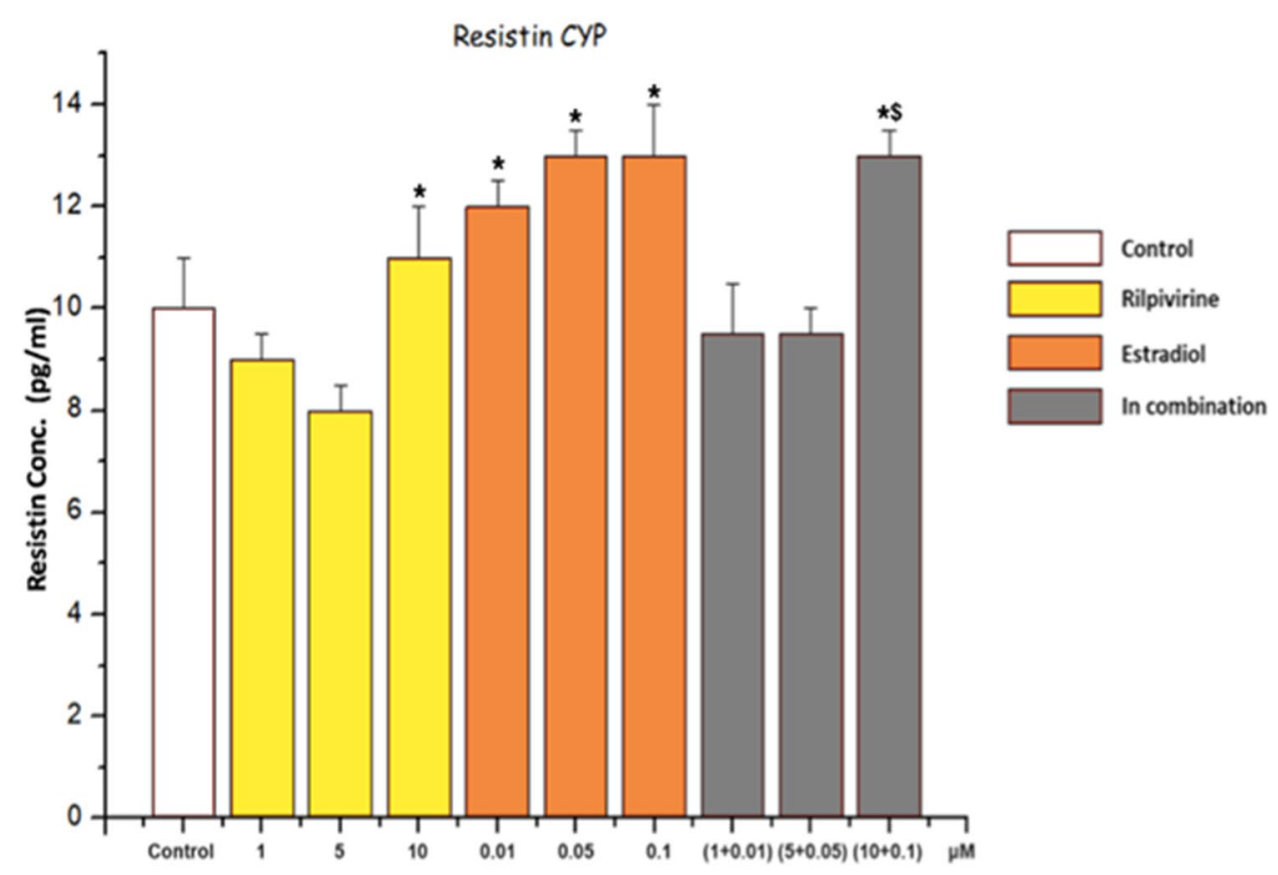


Fig. 11 Bar charts showing the effect rilpivirine and estradiol either alone or in combination and in the presence of $200 \mu \mathrm{M}$ of BNF on the release of interleukin- 8 from human adipocytes in culture for 10 days with all the drugs. Values are mean $\pm \mathrm{SD} ; \mathrm{n}=6$; * $\mathrm{p}<0.05$ for $1 \mu \mathrm{M}$ and 5 rilpivirine, 0.01 and $0.05 \mu \mathrm{M}$ estradiol compared to untreated cells

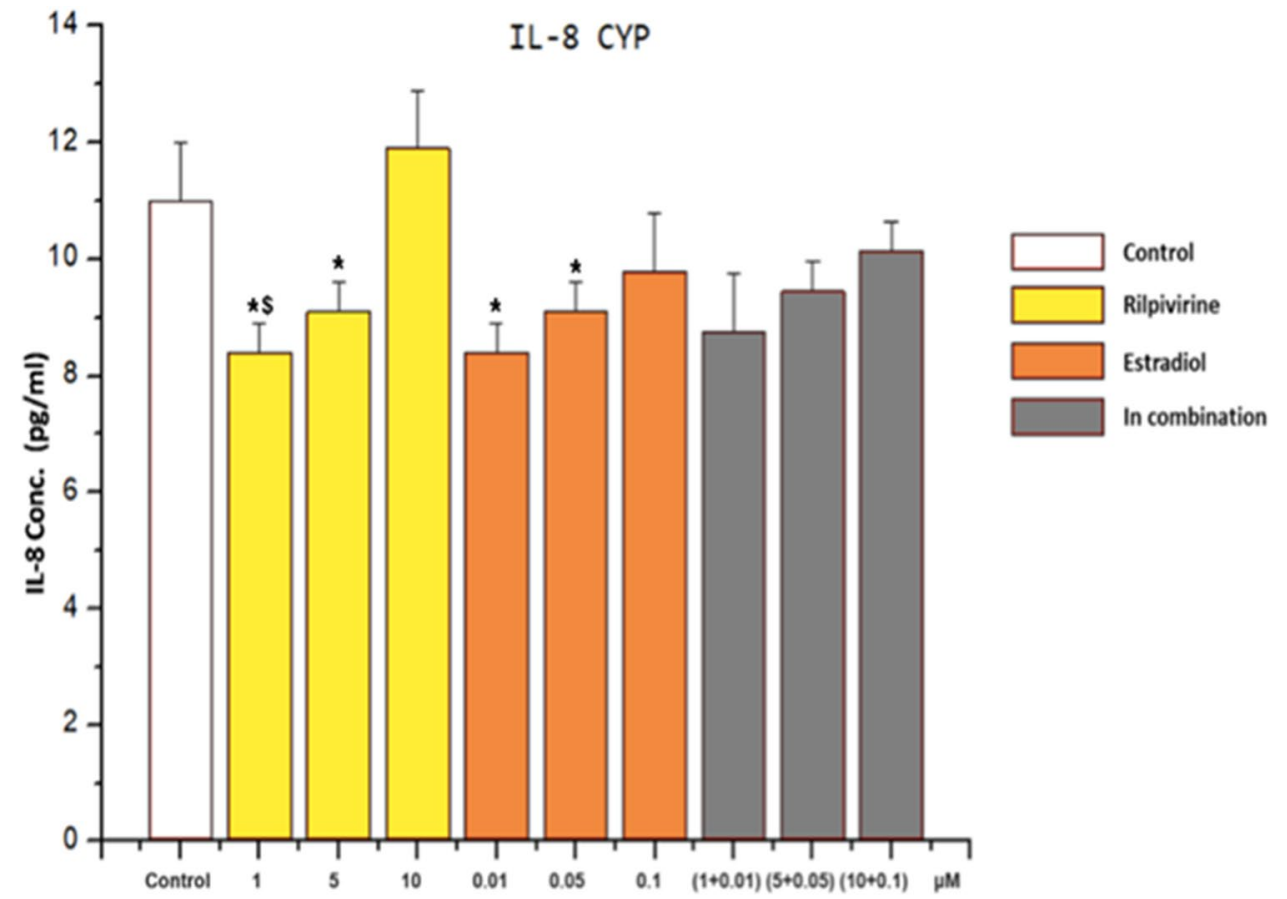

significant $(\mathrm{p}<0.05)$ decrease in the release of IL-8 for 1 and $5 \mu \mathrm{M}$ rilpivirine, 0.01 and $0.05 \mu \mathrm{M}$ estradiol compared to untreated cells.

\section{Discussion}

The results of this study have demonstrated marked morphological changes in the adipocytes in culture over time. The cells were observed daily as they were proceeding through the foregoing stages of differentiation. Microphotographs were taken on day 0 , day 5 and day 10 for comparison. The results show that the shape of the cells changed from the spindle- shaped fibroblast to the nearly spherical form of a mature adipose cell. There was an increasing accumulation of lipid, first as small inclusions concentrated towards one pole of the cell and then finally as large lipid masses in the central region of the cell.

Viability of the cells were assessed on 0,5 and 10th day of the adipocyte maturation process by employing lactate dehydrogenase as a marker to monitor cell death. Increasing concentrations of rilpivirine $(1 \mu \mathrm{M}, 5 \mu \mathrm{M}$ and $10 \mu \mathrm{M})$ and estradiol $(0.01 \mu \mathrm{M}, 0.05 \mu \mathrm{M}$ and $0.1 \mu \mathrm{M})$ were tried individually and in combination. The results clearly show that neither rilpivirine nor estradiol either alone or in combination with or without BNF had any deleterious effects on the viability of adipocytes compared to untreated cells. There was no significant release of LDH in stimulated or treated cells as compare to untreated cells. The viability of cells at all stages of adipogenesis, as measured by the lactate dehydrogenase assay, did not show any significant difference as compared to the control. Therefore, all these concentrations were determined as optimal for future experimental work. These results are in agreement with a previous study [26].

Data from several previous studies have revealed that anti-retroviral and estrogen therapy induces lipid alterations by activating lipolysis and thereby, enhancing the levels of free fatty acid and free glycerol in adipocyte cell cultures [27-29].

The results of this study show an increasing trend in the lipolysis process in human adipocytes. The release of glycerol was dose-dependent with both rilpivirine and estradiol. Concomitant treatment of two drugs at all doses did not show any attenuation or potentiating effect on glycerol release, but only a small additive effect compared to the effect of either rilpivirine or estradiol alone. The observed results could be attributed to impaired GLUT4 translocation and are in keeping with another study that assessed the effect of nelfinavir on glucose uptake and lipolysis in differentiated 3T3-L1 adipocytes [30]. An 18-h exposure to nelfinavir resulted in an impaired insulin-stimulated glucose uptake and activation of basal lipolysis with as low as $5 \mu \mathrm{mol} / \mathrm{l}$ nelfinavir [30]. Another study conducted in vivo showed that exposure to high concentrations of estradiol led to region-and pathway-dependent modulation of subcutaneous adipose tissue lipolysis in pre-menopausal women [31].

Leptin has been reported to be related to adiposity and it increases in proportion to decreasing adipose tissue stores. It is of much interest in anti-retroviral and estrogen-based 
therapies where abnormalities of body fat distribution are characteristic features. A number of in vitro studies have demonstrated a reduction in leptin secretion when human adipocytes were treated with ARVs [32,33]. In this study, no significant release in leptin level were observed when adipocytes were treated with either all concentrations of estradiol or low doses of rilpivirine compared to a higher dose of $10 \mu \mathrm{M}$ which elicited a significant decrease in leptin secretion compared to untreated cells. Similar results were obtained with the highest dose of each drug when they were combined. Previous in vivo and in vitro studies reported that estrogens can elevate the level of leptin [34, 35].However, some reports have indicated either a nil or a reverse relationship between estrogens and leptin release [36, 37].

Adiponectin, an insulin-sensitizing adipokine, is induced during adipocyte differentiation [38]. Reduced levels of adiponectin have been reported by various studies in adipocytes treated with very high doses of ARV drugs. In the present study, except for at a low concentration $(1 \mu \mathrm{M})$ of rilpivirine alone, all the other drug treatments elicited significant effects on the release of adiponectin levels from human adipocytes. Combining rilpivirine with estradiol produced a much larger decrease in the release of adiponectin compared to their individual concentrations alone. Adiponectin is known to enhance insulin-mediated glucose uptake in peripheral tissues (i.e., skeletal muscle) and in sensitizing liver to insulindependent suppression of glucose output [39]. This reduction may be considered as a major contributor to insulin resistance (IR). In this study, reduced levels of adiponectin were observed when cells were treated with increasing doses of $17 \beta$-estradiol. The present results are in agreement with a recent study that reported dramatically suppressed levels of adiponectin concentration when pre-adipocytes were exposed to increasing levels of $17 \beta$-estradiol [40].

Originally, resistin was thought to be a link between diabetes and obesity. A single nucleotide polymorphism in the resistin gene has been associated with elevated lipids, IR and body composition changes among HIV-infected individuals on anti-retroviral therapies [41]. In another study, greater plasma resistin levels were observed in HIV patients compared with uninfected controls [42]. However, other workers have found no association between serum resistin and fat redistribution, and metabolic profile in $\mathrm{HIV}$-infected patients $[43,44]$. The physiological role of resistin, therefore, is not fully understood and needs further studies. It is proposed to be an important peptide bringing about IR and obesity, although it is still debatable [45].In the present study, the levels of resistin were comparable to that of control and there was no significant difference for pre-adipocytes treated individually with rilpivirine at low doses. Only a slight increase in the resistin level was observed at $10 \mu \mathrm{M}$, indicating that rilpivirine may contribute to the fat re-distribution but only at high dosage. A positive correlation in estrogens and resistin levels has been demonstrated and resistin concentrations were found to be conspicuously elevated by $17 \beta$-estradiol $[40,46]$. The present study showed enhanced levels of resistin in adipose cells treated with different concentrations of $17 \beta$-estradiol as compared to control. Combination of rilpivirine and estradiol did not show any increase in resistin level for the lowest and median doses used in the study. However, an increase in the resistin concentrations was observed at the highest dosage of combination treatment ( $1 \mu \mathrm{M}$ rilpivirine combined with $0.1 \mu \mathrm{M}$ estradiol).

Increased serum IL-8 levels have been previously reported in HIV patients with impaired glucose tolerance [47], and this is consistent with findings in T2DM [48], obesity and non-alcoholic fatty liver disease [49]. Chronic inflammatory state in HIV-infection may be associated with elevated fasting serum level of IL-8. Higher serum IL-8 may also reflect increased production and release from the larger adipose depots and may have an influence on lipid metabolism along with its effect on insulin resistance. Elevated levels of IL-8 have been observed in human subcutaneous and visceral adipose tissue obtained from HIV-infected people with fat redistribution and insulin resistance [50]. In the present study, IL-8 levels increased with an increase in the concentrations of rilpivirine. High concentrations of IL-8 were observed when the cells were treated with $10 \mu \mathrm{M}$ of rilpivirine indicating its role in fat re-distribution. The present findings are in agreement with another study [26], which reported that rilpivirine did not have any effect on the release of IL- 8 at concentrations up to $4 \mu \mathrm{M}$, but instead, it produced a marked and significant elevation only at $10 \mu \mathrm{M}$. Compared to rilpivirine, estradiol evoked a dose-dependent increase in the release of IL- 8 from adipose cells. Enhanced levels of IL-8 were observed when the pre-adipocytes were treated with increasing concentrations of estradiol. Moreover, increasing release in the level of IL-8 was observed when adipocytes were treated with a combination of rilpivirine and estradiol suggesting a major contribution of estradiol in eliciting the release of IL-8.

In the second series of experiments human adipocytes were pretreated with BNF in the absence and presence of either rilpivirine, estradiol or when the two drugs were combined for a period of 10 days. The results reveal elevated glycerol level with BNF alone. When BNF was combined with either rilpivirine, estradiol or both drugs, there were enhanced release of glycerol in a dose-dependent manner. BNF seems to be potentiating the effect of either rilpivirine or estradiol on glycerol release (enhanced lipolysis) from human adipocytes. In contrast, BNF had no significant effect on the release of leptin from human adipocytes when combined with either rilpivirine, estradiol or with both. In this series, BNF also enhanced the decrease in adiponectin release from human adipocytes in the presence of either rilpivirine, estradiol or when the two drugs were combined 
compared to the results obtained in the absence of BNF. In contrast, in the presence of BNF, individual treatment of adipose cells with either rilpivirine or estradiol alone or combined did not seem to have any significant effect on the resistin and IL-8 releases for all the doses used in the study compared to the results obtained in the absence of BNF. In fact $\mathrm{BNF}$ seemed to induce a reduction in the levels of resistin and IL-8 as compared to levels in the absence of BNF.

\section{Conclusion}

From the results of this study, it is possible to conclude that a combination of rilpivirine and $17 \beta$-estradiol is completely non-toxic to pre-adipocytes at most concentrations tested. During the 10-day exposure to the drugs, only estradiol produced a modest cytotoxic effect at the highest concentrations. No profound deleterious effect was on adipose tissue development or the endocrine function of adipose tissue (adipokine and cytokine release) in treated 3T3-L1 human pre-adipocytes. However, caution should be maintained considering that other transcriptional factors play a crucial role in overall alterations of lipid metabolism. BNF does not seem to significantly interact with rilpivirine and $17 \beta$-estradiol except for the release of adiponectin. Moreover, in order to establish and elucidate a significant effect of these drugs on the adipogenic process, studies at gene expression levels and involving the markers of oxidative stress are required.

\section{Compliance with Ethical Standards}

Conflict of interest The authors declare no conflict of interests with respect to the present paper.

Open Access This article is distributed under the terms of the Creative Commons Attribution 4.0 International License (http://creativeco mmons.org/licenses/by/4.0/), which permits unrestricted use, distribution, and reproduction in any medium, provided you give appropriate credit to the original author(s) and the source, provide a link to the Creative Commons license, and indicate if changes were made.

\section{References}

1. Zimmet P, Magliano D, Matsuzawa Y, Albert G (2005) The metabolic syndrome: a global public health problem and a new definition. J Atheroscler Thromb 12:295-300

2. Ness-Abramof R, Caroline MA (2005) Drug-induced weight gain. Drugs Today 41(8):547-555

3. Ratliff JC, Jessica A, Laura B, Erin L, Cenk T (2010) Association of prescription $\mathrm{H} 1$ antihistamine use with obesity: results from the National Health and Nutrition Examination Survey. Obesity (Silver Spring Md) 18(12):2398-2400

4. Cohen CJ, Andrade-Villanueva J, Clotet B, Fourie J, Johnson MA, Ruxrungtham K, Wu H, Zorrilla C, Crauwels H, Rimsky LT, Vanveggel S, Boven K (2011) Rilpivirine versus Efavirenz with two background nucleoside or nucleotide reverse transcriptase inhibitors in treatment-naive adults infected with HIV-1 (THRIVE): a phase 3, randomised, non-inferiority trial. The Lancet 378(9787):229-237. https://doi.org/10.1016/S0140 -6736(11)60983-5.

5. Molina JM, Cahn P, Grinsztejn B, Lazzarin A, Mills A, Saag M, Supparatpinyo K, Walmsley S, Crauwels H, Rimsky LT, Vanveggel S, Boven K (2011) Rilpivirine versus efavirenz with tenofovir and emtricitabine in treatment-naive adults infected with HIV-1 (ECHO): a phase 3 randomised double-blind activecontrolled trial. The Lancet 378(9787):238-246

6. Wilkin A, Anton LP, Javier M, Sergio H, Mario S, Beatriz G, Kiat R, Laurence TR, Simon V, Katia B (2012) Long-term efficacy, safety, and tolerability of rilpivirine (RPV, TMC278) in HIV type 1-infected antiretroviral-naive patients: week 192 results from a phase IIb randomized trial. AIDS Res Hum Retroviruses 28(5):437-446

7. Tebas P, Michael S, José A, Dan D, Eric F, Chien C, Timothy W, Simon V, Marita S, Henri D (2014) Lipid levels and changes in body fat distribution in treatment-naive, HIV-1-infected adults treated with rilpivirine or efavirenz for 96 weeks in the ECHO and THRIVE trials. Clin Infect Dis 59(3):425-434

8. Hausman DB, DiGirolamo M, Bartness TJ, Hausman GJ, Martin RJ (2001) The biology of white adipocyte proliferation. Obes Rev 2(4):239-254

9. Thorn SR, Meyer MJ, Van Amburgh ME, Boisclair YR (2007) Effect of estrogen on leptin and expression of leptin receptor transcripts in prepubertal dairy heifers. J Dairy Sci 90(8):3742-3750

10. Matelski H, Greene R, Huberman M, Lokich J, Zipoli T (1985) Randomized trial of estrogen vs. tamoxifen therapy for advanced breast cancer. Am J Clin Oncol 8(2):128-133

11. Kuiper GG, Enmark E, Pelto-Huikko M, Nilsson S, Gustafsson JA (1996) Cloning of a novel receptor expressed in rat prostate and ovary. Proc Natl Acad Sci USA 93(12):5925-5930

12. Dieudonne MN, Pecquery R, Leneveu MC, Giudicelli Y (2000) Opposite effects of androgens and estrogens on adipogenesis in rat preadipocytes: evidence for sex and site-related specificities and possible involvement of insulin-like growth factor 1 receptor and peroxisome. Endocrinology 141(2):649-656

13. Anderson LA, McTernan PG, Barnett AH, Kumar S (2001) The effects of androgens and estrogens on preadipocyte proliferation in human adipose tissue: influence of gender and site. J Clin Endocrinol Metab 2001 Oct 86(10):5045-5051

14. Taylor GP, Clayden P, Dhar J, Gandhi K, Gilleece Y, Harding K, Hay P et al (2012) British HIV association guidelines for the management of HIV infection in pregnant women 2012. HIV Med 13(Suppl 2):87-157

15. Rimsky L, Van Eygen V, Hoogstoel A, Stevens M, Boven K, Picchio G, Vingerhoets J Phase III (2013) 96-Week resistance analyses of rilpivirine in treatment-naive, HIV-1-infected adults from the ECHO and THRIVE. Trials Antivir Ther 18(8):967-977

16. Brown KC, Sunita P, Angela DM (2009) Drug interactions with new and investigational antiretrovirals. Clin Pharmacokinet 48(4):211-241

17. Yoshinari K, Takeshi S, Nao O, Junko S, Masao M (2004) Expression and induction of cytochromes $\mathrm{P} 450$ in rat white adipose tissue. J Pharmacol Exp Ther 311(1):147 LP-L154

18. Müllerová D, Kopecký J (2007) White adipose tissue: storage and effector site for environmental pollutants. Physiol Res 56(4):375-381 
19. Elobeid Mai A, David BA (2008) Putative environmental-endocrine disruptors and obesity: a review. Curr Opin Endocrinol Diabetes Obes

20. Feige JN, Laurent G, Daniel R, Vincent Z, Raphaël M, Cicerone T, Silvia I et al (2007) The endocrine disruptor monoethylhexyl-phthalate is a selective peroxisome proliferator-activated receptor $\gamma$ modulator that promotes adipogenesis. J Biol Chem 282(26): 19152-19166

21. Uemura H, Kokichi A, Mineyoshi H, Hiroshi S, Yoshio S, Kenji M, Kazunori K, Taka-ichiro S, Masaki N, Tsuguyoshi S (2008) Associations of environmental exposure to dioxins with prevalent diabetes among general inhabitants in Japan. Environ Res 108(1):63-68

22. Yoshinari K, Okino N, Sato T, Sugatani J, Miwa M (2006) Induction of detoxifying enzymes in rodent white adipose tissue by aryl hydrocarbon receptor agonists and antioxidants. Drug Metab Dispos 34(7):1081-1089

23. Arinç E, Orhan A, Ayse M (2000) Induction of N-nitrosodimethylamine metabolism in liver and lung by in vivo pyridine treatments of rabbits. Arch Toxicol 74(6):329-334

24. Shimada T, Hiroshi Y, Maryam F, Nancy EH, William LA, Peter (1998) Selectivity of polycyclic inhibitors for human cytochrome P450s 1A1, 1A2, and 1B1. Chem Res Toxicol 11(9):1048-1056

25. Safe S, Syng-Ook L, Un-Ho J (2013) Role of the aryl hydrocarbon receptor in carcinogenesis and potential as a drug target. Toxicol Sci 135(1):1-16

26. Díaz-Delfín J, Pere D, Maria GM, Maria G, Joan CD, Marta G, Francesc V (2012) Effects of rilpivirine on human adipocyte differentiation, gene expression, and release of adipokines and cytokines. Antimicrob Agents Chemother 56(6):3369-3375

27. Mallon PW (2007) Antiretroviral therapy-induced lipid alterations: in-vitro, animal and human studies. Current Opinion in HIV AIDS 2(4):282-292

28. Jones SP, Catriona W, Robert S, David JB, Munir (2008) Effect of atazanavir and ritonavir on the differentiation and adipokine secretion of human subcutaneous and omental preadipocytes. Aids 22(11):1293-1298

29. Ranganathan S, Kern P (2002) The HIV protease inhibitor saquinavir impairs lipid metabolism and glucose transport in cultured adipocytes. J Endocrinol 172(1):155-162

30. Rudich A, Vanounou S, Riesenberg K, Porat M, Tirosh A, Harman-Boehm I, Greenberg AS, Schlaeffer F, Bashan N (2001) The HIV protease inhibitor nelfinavir induces insulin resistance and increases basal lipolysis in 3T3-L1 adipocytes. Diabetes 50(6):1425 LP-L1431

31. Gavin KM, Cooper EE, Raymer DK, Hickner RC (2013) Estradiol effects on subcutaneous adipose tissue lipolysis in premenopausal women are adipose tissue depot specific and treatment dependent. Am J Physiol Endocrinol Metab 304(11):E1167-E1174

32. Ambati S, Hye-Kyeong K, Jeong-Yeh Y, Ji L, Mary A, Clifton AB (2007) Effects of leptin on apoptosis and adipogenesis in 3T3-L1 adipocytes. Biochem Pharmacol 73(3):378-384

33. Díaz-Delfín J, Gutiérrez M, Gallego-Escuredo J, Domingo J, Gracia Mateo M, Francesc V, Pere D, Marta G (2011) Effects of nevirapine and efavirenz on human adipocyte differentiation, gene expression, and release of adipokines and cytokines. Antiviral Res 91(2):112-119

34. Ainslie DA, Morris MJ, Wittert G, Turnbull H, Proietto J, Thorburn AW (2001) Estrogen deficiency causes central leptin insensitivity and increased hypothalamic neuropeptide Y. Int J Obes 25(11):1680-1688

35. Geber S, Augusto HF, Marcos S (2012) Effects of estradiol and FSH on leptin levels in women with suppressed pituitary. Reprod Biol Endocrinol 10(1):45

36. Rechberger T, Wlodzimierz B, Krzysztof P, Artur J, Jacek T, Beata KR, Jerzy AJ (1999) Serum leptin concentrations in women taking oral contraceptives. Eur J Obstet Gynecol Reprod Biol 83(1): $105-108$

37. Xing Y, Liu J, Xu J, Yin L, Wang L, Li J, Yu Z, Li F, Gao R, Jia J (2015) Association between plasma leptin and estrogen in female patients of amnestic mild cognitive impairment. Dis Mark. https ://doi.org/10.1155/2015/450237

38. Scherer PE, Williams S, Fogliano M, Baldini G, Lodish HF (1995) A novel serum protein similar to $\mathrm{C} 1 \mathrm{q}$, produced exclusively in adipocytes. J Biol Chem 270(45):26746-26749

39. Kadowaki T, Toshimasa Y, Naoto K, Kazuo H, Kohjiro U, Kazuyuki T (2006) Adiponectin and adiponectin receptors in insulin resistance, diabetes, and the metabolic syndrome. J Clin Investig 116(7):1784-1792

40. Pektaş M, Akif H, İsmail Ü, Rukiye N, Kansu B (2015) Effects of $17 \beta$-estradiol and progesterone on the production of adipokines in differentiating 3T3-L1 adipocytes: role of Rho-kinase. Cytokine 72(2):130-134

41. Steppan CM, Shannon T, Savitha B, Elizabeth JB, Ronadip RB, Christopher MW, Hiralben RP, Rexford SA, Mitchell AL (2001) The hormone resistin links obesity to diabetes. Nature 409(January):307

42. Escoté X, Merce M, Sergi V, Pere D, Carlos A, Joaquim P, Consuelo $\mathrm{V}$ et al (2011) Lipodystrophy and insulin resistance in combination antiretroviral treated HIV-1-infected patients: implication of resistin. J Acquir Immune Defic Syndr 57(1):16-23

43. Barb D, Sanjivini GW, Juergen K, Alina G, Jean LC, Catherine JW, Adolf WK, Christos SM (2005) Circulating resistin levels are not associated with fat redistribution, insulin resistance, or metabolic profile in patients with the highly active antiretroviral therapy-induced metabolic syndrome. J Clin Endocrinol Metab 90(9):5324-5328

44. Arama V, Munteanu DI, Streinu C, Ion DA, Mihailescu R, Tiliscan C, Tudor AM, Arama SS (2014) Lipodystrophy syndrome in HIV treatment-multiexperienced patients: implication of resistin. J Endocrinol Invest 37(6):533-539

45. Lappas M, Yee K, Permezel M, Rice GE (2005) Release and regulation of leptin, resistin and adiponectin from human placenta, fetal membranes, and maternal adipose tissue and skeletal muscle from normal and gestational diabetes mellitus-complicated pregnancies. J Endocrinol 186(3):457-465

46. Chen YH, Meng-Jung L, Hsin-Huei C, Pei-Fang H, Yung-Hsi K (2006) $17 \beta$-estradiol stimulates resistin gene expression in 3T3$\mathrm{L} 1$ adipocytes via the estrogen receptor, extracellularly regulated kinase, and CCAAT/enhancer binding protein- $\alpha$ pathways. Endocrinology 147(9):4496-4504

47. Reeds DN, WTodd C, Bruce WP, William GP, Samuel K, Kevin EY (2006) Whole body proteolysis rate is elevated in HIV-associated insulin resistance. Diabetes 55(10):2849-2855

48. Zozulinska D, Majchrzak A, Sobieska M, Wiktorowicz K, Wierusz-Wysocka B (1999) Serum interleukin-8 level is increased in diabetic patients. Diabetologia 42(1):117-118

49. Jarrar MH, Baranova A, Collantes R, Ranard B, Stepanova M, Bennett C, Fang Y, Elariny H, Goodman Z, Chandhoke V, Younossi ZM (2008) Adipokines and cytokines in non-alcoholic fatty liver disease. Aliment Pharmacol Ther 1;27(5):412-421

50. Lihn A, Bjørn R, Steen BP, Steen BH, Gulla SR, Sten M, Ove A (2003) Increased expression of TNF- $\alpha$, IL-6, and IL-8 in HALS: implications for reduced adiponectin expression and plasma levels. Am J Physiol-Endocrinol Metab 285(5):E1072-E1080

Publisher's Note Springer Nature remains neutral with regard to jurisdictional claims in published maps and institutional affiliations. 